between the scientific and the business world, which is one of the objects of such societies, is of great value; in the past the tendency has been too much towards work in separate and unconnected compartments. The Society has decided to divide the membership into two classes designated respectively "members" and "associates," the former being those who are professionally connected with lighting, and the latter those who are incidentally interested in one or other special aspects of illumination. The annual subscription for the former is to be two guineas and for the latter, which includes students, one guinea.

Joint committees on railway lighting, street lighting, school lighting, etc., have been formed. A special joint committee on eye-strain in cinema theatres and its prevention has been formed in which the Council of British Ophthalmologists is represented by Messrs. J. H. Parsons, C.B.E. (chairman), Mayou, McMullen, O.B.E., and Cridland, and the Physiological Society by Professors Bayliss, Shearman, Sherrington, and MacDougal. The Illuminating Engineering Society, the Cinema Industry, the Fire Brigade, and the Education Department of the London County Council are also worthily represented. We confidently look forward to valuable results in this connection.

\title{
Injuries to the Eye by Poison Gas
}

Little has been published in English upon injuries to the eye by poison gas*, although many such cases have been seen in this country by individual observers. It is therefore with all the more pleasure that we welcome a discussion of the subject held at the last meeting of the American Ophthalmological Society. Dr. H. G. S. Derby, late assistant consultant in ophthalmology to the American Expeditionary Forces, pointed out that the so-called lacrimatory gas was only one of the varieties of gas used by the Germans for the purposes of disabling their enemies. It caused burning pain, copious lacrimation, photophobia, and injection of the conjunctiva. Exfoliation of the epithelial covering of the cornea was liable to follow exposure to the fumes. The milder cases recovered quickly. Even those of a more severe nature were usually well within two weeks. Injuries from mustard gas were much more 'serious. Its action was not noticed until from two to six hours after exposure to the fumes, when severe erythema of the skin developed, followed by blistering, the moist parts of the body being most severely affected. In severe cases bronchitis and secondary pneumonia were observed. There was profuse lacrimation and considerable

${ }^{*}$ Two papers dealing with gas injuries to the eyes have been recently published in this journal, namely: J. A. Pringle, March, 1919; Wallace, November, 1919. 
injection of the conjunctiva. Mild cases formed 75 per cent. to 80 per cent. of those affected. In the remainder the lids showed redness and swelling, and often the formation of bullae. All attempts to open the lids gave rise to pain. The conjunctiva was markedly injected and might be in a state of chemosis. In severely burned eyes there was often an area of solid white oedema of the conjunctiva in the palpebral fissure. The corneal lesions varied in severity, but principally consisted of a roughening of the epithelium with irregular, greyish scattered areas of opacity. The most severe cases showed a whitish band crossing the cornea in the area of the palpebral fissure. The lesions produced by mustard gas are in the nature of a chemical burn. In mild cases recovery may take place in from one to two weeks, and the others may last from four weeks to four months. A neurotic condition, hard to overcome, may be set up by the injury to the eye. Prevention calls for the gas mask. Cure is retarded by bandaging the injured eye. Exposed eyes should be washed out often with sodium carbonate or boric acid solution. A drop of some oil, such as liquid albolene, should be instilled. When much blepharospasm and irritation are present, atropin should be used. A shade or dark glasses should be -worn. Protargol, argyrol, weak zinc sulphate, all may have their places in the treatment of the condition. Dr. F. H. Verhoeff, who had seen a number of these cases after their return to America, believed that the badly exposed men would have more or less trouble with their eyes all their lives. Dr. Allen Greenwood, late senior consultant in ophthalmology to the American Expeditionary Forces, emphasized the necessity of early treatment, the avoidance of bandages and the hospitalization of the patients. Dr. Nelson M. Black, late consultant in ophthalmology to the American Expeditionary Forces, recommended that when the patient felt that he must protect his eyes in some way from the light, he should make eye shades from the blue paper that was wrapped around packets of absorbent cotton wool.

\section{ABSTRACTS}

\section{I.-REMEDIES}

(I) Sculco, Nicolas (Catanzaro, Italy). The new therapeusis of trachoma. (La nouvelle thérapeutique du trachome.) La Clin. Ophtal., February, 1919.

(1) However pessimistic one may have become as to the value of new remedies for rebellious diseases, it is always right that the 